\title{
Global DNA hypomethylation occurs in the early stages of intestinal type gastric carcinoma
}

\author{
M Cravo, R Pinto, P Fidalgo, P Chaves, L Glória, C Nobre-Leitão, F Costa Mira
}

\begin{abstract}
Background-Global DNA hypomethylation has been found in the premalignant stages of some neoplasms and has been implicated as an important factor for tumour progression.

Aims-The aim of this study was to evaluate whether DNA hypomethylation occurs during the process of gastric carcinogenesis.

Methods-Gastric specimens were obtained from 49 patients and histologically classified as: normal 10, superficial gastritis 14, chronic atrophic gastritis with intestinal metaplasia 15, and intestinal type of gastric carcinoma 10. Global DNA methylation was assessed by incubating DNA with $\left({ }^{3} \mathrm{H}\right)$-S-adenosylmethionine and Sss1 methylase. A higher incorporation of $\left.{ }^{3} \mathrm{H}\right)$ methyl groups reflects a lower degree of intrinsic methylation.

Results-A graduated increase in $\left({ }^{3} \mathrm{H}\right)$ methyl group incorporation into DNA was found over the range extending from normal gastric mucosa, to superficial gastritis and to chronic atrophic gastritis (136556 (24 085) v 235725 (38 636) v 400998 (26747 dpm/ $\mathrm{gg} / \mathrm{DNA}$ respectively; $p=0.0002)$. No further increase was found in specimens from patients with carcinoma. No differences were found between extent of DNA methylation in neoplastic or non-neoplastic mucosa from patients with gastric carcinoma. Hypomethylation of DNA increased substantially with severe atrophy $(p=0.01)$ or with type III intestinal metaplasia $(p=0 \cdot 15)$.

Conclusions-Global DNA hypomethylation occurs in the early stages of gastric carcinogenesis, and it may be a novel biomarker of gastric neoplasia, useful in monitoring the response to chemopreventive agents.

(Gut 1996; 39: 434-438)
\end{abstract}

Keywords: DNA methylation, gastric carcinogenesis, intermediate biomarker.

Molecular

M Cravo

Serviço de Patologia Morfológica

P Chaves

Instituto Português de Oncologia, Francisco Gentil, Lisbon, Portugal

Correspondence to:

Dr M Cravo,

Serviço de Gastrenterologia Instituto Português de Oncologia Francisco Gentil, 1093 Lisbon codex, Portugal. Accepted for publication 16 April 1996

According to previous epidemiological and morphological studies, the intestinal type of gastric cancer is preceded by a series of precursor lesions - namely, superficial gastritis, chronic gastritis, atrophy, intestinal metaplasia, dysplasia, intramucosal carcinoma, and invasion. ${ }^{1-7}$ However, both chronic atrophic gastritis and intestinal metaplasia are significantly age related and extremely common in the older age groups, both in benign and malignant conditions, which may limit its predictive value as an indicator of risk. This has prompted a number of studies aimed at identifying other phenotypic markers of risk that may help to recognise subgroups of patients at increased risk who could then be included in surveillance and chemoprophylactic programmes. These studies found that severe atrophy and incomplete type III intestinal metaplasia are strongly associated with intestinal type gastric cancer..$^{8-10}$

This model of gastric carcinogenesis in which the mucosa evolves through a series of sequential changes, is extremely useful to study genetic or epigenetic phenomena, which may occur at several stages of tumour development and which may also serve as intermediate biomarkers. Similar to colorectal carcinogenesis, several genetic events have been described in this sequence of premalignant changes, ${ }^{1112}$ although the exact order in which they occur is still debatable. Allelic deletions of APC/ MCC and p53 tumour suppressor genes, as well as mutations of $\mathrm{K}$-ras proto-oncogene, or amplification of c-erbB-2 oncogene, are among the most commonly described events. ${ }^{13-15}$ Alterations in DNA methylation patterns are known to precede the development of a wide variety of human and animal cancers ${ }^{16-24}$ and have not been previously studied in gastric carcinogenesis. Both global hypomethylation and regional hypermethylation may occur simultaneously during various stages of tumour progression. $^{25-28}$

Potential mechanisms whereby dysregulation of DNA methylation patterns may promote malignant transformation include altered gene expression, increased rate of mutations secondary to deamination of 5-methylcytosine, or alterations in DNA conformation and chromatin structure. ${ }^{29-33}$

The aims of this study were to examine a possible relation between global DNA methylation level and the histological changes that have been identified as precursors of the intestinal type of gastric carcinoma.

\section{Methods}

Patients

The study was approved by the ethics and scientific committee of our Institution.

Thirty nine patients referred to the gastroenterology department of the Instituto Português de Oncologia at Lisbon for an upper gastrointestinal endoscopy between June 1994 and January 1995, were included in the study. Patients requiring emergency endoscopy were excluded, as well as patients with present or previous neoplastic disease, previous gastric 
surgery, and gastric or duodenal ulcer. Patients with normal endoscopy and those with antral abnormalities varying from mild erythema to full blown endoscopic gastritis were included. Additionally, 10 other patients with a diagnosis of intestinal type gastric carcinoma of the antrum referred for surgery during the same period, also entered the study. Thus a total of 49 patients with either normal findings $(n=10)$ or with superficial gastritis $(n=14)$, chronic atrophic gastritis $(n=15)$, or intestinal type gastric carcinoma $(n=10)$ were included in the study. The Table shows the age and sex distributions of the four groups.

In patients submitted to upper endoscopy, gastric biopsy specimens were taken as follows: a minimum of two from the antrum (midportion of antral lesser and greater curvatures), one from the transition zone, and at least one from the body, midanterior wall. Most of the time additional specimens were taken and any macroscopically identifiable lesions were biopsied. Four to five biopsy specimens were also taken from the antrum, frozen in liquid nitrogen, and kept at $-70^{\circ} \mathrm{C}$ for later assessment of DNA methylation. In patients with gastric cancer submitted to surgery, two fragments of $5 \mathrm{~mm}$ each were sectioned from the surgical specimen at the time of operation (from neoplastic and non-neoplastic mucosa), immediately frozen in liquid nitrogen, and stored at $-70^{\circ} \mathrm{C}$ for DNA extraction. All biopsy and surgical specimens were fixed in $10 \%$ formalin, embedded in paraffin wax, and stained with haematoxylin and eosin. Special stainings for Helicobacter pylori detection were not used. The non-neoplastic mucosa was classified according to Correa. ${ }^{34}$ The neoplasms were histologically classified according to Lauren ${ }^{35}$ and staged according to Union Internationale Contre Le Cancer criteria. ${ }^{36}$ Biopsy specimens showing intestinal metaplasia were stained with Alcian blue $\mathrm{pH}$ 2.5/periodic acid Shiff ${ }^{1}$ and high iron diamine/ Alcian blue $\mathrm{pH} 2 \cdot 5^{2}$ to identify subtypes of intestinal metaplasia. ${ }^{37}$ These were classified as described by Filipe and Jass. ${ }^{10}$

\section{Global DNA methylation assay}

The DNA from gastric biopsy specimens was extracted with a previously described method. ${ }^{38}$

Clinical and pathological characteristics of the patients included in the study

\begin{tabular}{lllll}
\hline Histology & $\begin{array}{l}\text { Normal } \\
(n=10)\end{array}$ & $\begin{array}{l}S G \\
(n=14)\end{array}$ & $\begin{array}{l}C A G \\
(n=15)\end{array}$ & $\begin{array}{l}G C \\
(n=10)\end{array}$ \\
\hline Mean age (range) (y) & $61(39-82)$ & $63(20-81)$ & $59(38-73)$ & $64(44-74)$ \\
Sex (M:F) & $5: 5$ & $5: 9$ & $9: 6$ & $6: 4$ \\
Activity of gastritis: & & $5(36)$ & $6(40)$ & \\
$\quad$ None & $4(29)$ & $5(33)$ & \\
Mild & $2(14)$ & $1(7)$ & \\
Moderate & $3(21)$ & $3(20)$ & \\
Severe & & $7(47)$ & \\
Degree of atrophy: & & & $3(20)$ & \\
$\quad$ Mild & & $5(33)$ & \\
Moderate & & $8(57)$ & $8(53)$ & \\
Severe & $6(43)$ & $7(47)$ & \\
Helicobacter pylori: & & & \\
Positive & & & \\
Negative & & &
\end{tabular}

$\mathrm{SG}=$ superficial gastritis; $\mathrm{CAG}=$ chronic atrophic gastritis; $\mathrm{GC}=$ gastric cancer.

Values in parentheses are $\%$ unless otherwise stated.
Differences in the extent of in vivo DNA methylation were determined by analysing DNA methyl accepting capacity in the presence of $\left({ }^{3} \mathrm{H}\right)$ S-adenosylmethionine and Sss 1 methylase. ${ }^{39}$ Briefly $2 \mu \mathrm{g}$ of DNA were incubated with $5 \mu \mathrm{Ci} \quad\left({ }^{3} \mathrm{H}\right)$-methylS-adenosylmethionine $\left(\left({ }^{3} \mathrm{H}\right)-\mathrm{SAM}, 3-10 \mathrm{mCi}\right.$ mmol, Amersham, UK) and four units Sss 1 methylase (New England Biolabs, Beverly, MA, USA) in 20:1 methylation buffer containing $5 \mathrm{mM}$ sodium chloride, $10 \mathrm{mM}$ TRIS, $10 \mathrm{mM}$ EDTA, and $1 \mathrm{mM}$ dithiothreitol, $\mathrm{pH}$ 8.0 for three hours at $37^{\circ} \mathrm{C}$. The reaction was stopped by incubating at $65^{\circ} \mathrm{C}$ for 20 minutes. The incubation mixtures were washed onto disks of Whatman DE-81 paper (Fisher Scientific, Springfield, NJ, USA) and then soaked in $50 \mathrm{ml}$ of $5 \%$ dibasic sodium phosphate. After drying, the radioactivity of the DNA retained in the discs was measured by scintillation counting. All measurements were done in duplicate. The manner in which this assay is performed produces a reciprocal relation between the endogenous DNA methylation status and the exogenous $\left({ }^{3} \mathrm{H}\right)$-methyl incorporation. Therefore, a higher incorporation of $\left({ }^{3} \mathrm{H}\right)$ methyl groups into DNA reflects a lower state of intrinsic methylation. Sss 1 methylase is a bacterial DNA methyltransferase that specifically catalyses the transfer of methyl groups from S-adenosylmethionine to cytosine residues in the cytosine-guanine doublet. In this regard, it shares the specificity of eukariotic DNA methyltransferase.

\section{Statistical analysis}

Differences among groups were tested by one way analysis of variance (ANOVA). Association between variables was assessed by regression analysis. Differences between proportions were determined using the $\chi^{2}$ test. Results are presented as mean (SEM). All tests are bilateral and the significance level was set at $5 \%$.

\section{Results}

According to histological classification, 10 patients were considered normal, 14 were classified as having superficial gastritis, and 15 as having chronic atrophic gastritis. The Table shows the degree of activity, atrophy, and the prevalence of $H$ pylori infection in specimens from patients with chronic gastritis. As far as patients with gastric cancer were concerned, one patient had stage I disease, four stage II, four stage III, and one stage IV disease. The non-neoplastic mucosa of these patients was examined as well. In nine of them, chronic atrophic gastritis was present, whereas superficial gastritis was found in only one.

As shown in the Figure, there was a significant and stepwise increase in $\left({ }^{3} \mathrm{H}\right)$ methyl group incorporation into DNA over the range extending from normal mucosa, to superficial gastritis and chronic atrophic gastritis (ANOVA, $p=0.0002$ ). However, no differences were found between the degree of DNA 


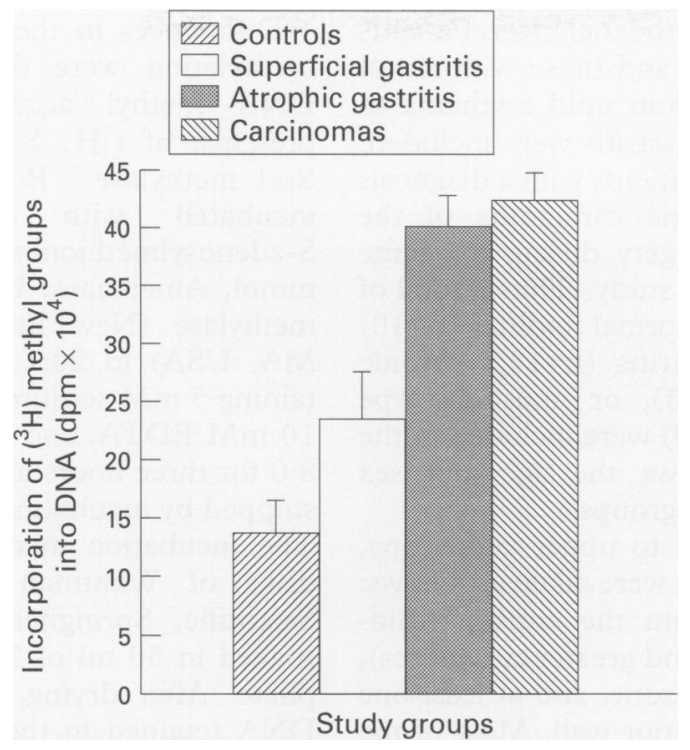

$\left.{ }^{\beta} H\right)$ methyl group incorporation into DNA from the four study groups. A higher degree of $\left({ }^{\beta} \mathrm{H}\right)$ methyl group incorporation reflects a lower degree of intrinsic DNA methylation. Hypomethylation of DNA increased progressively from controls, to superficial gastritis, to chronic atrophic gastritis (136556 (24 085) v 235725 (38 636) v 400998 (26 747) dpm/ $\mu g / D N A$ respectively). Differences were significant by ANOVA $(p=0.0002)$. No further increase was found in DNA from gastric carcinomas (424 482 (24 321) $d p m / \mu g / D N A)$. Data are presented as mean (SEM).

methylation in samples from patients with chronic atrophic gastritis and patients with gastric cancer. Also, in samples from patients with gastric carcinoma, the degree of tritiated methyl group incorporation was similar in DNA extracted from non-neoplastic mucosa and in DNA from the neoplasm itself (408 605 (32 322) $v 424482$ (24 321) $\mathrm{dpm} / \mu \mathrm{g} / \mathrm{DNA}$ respectively).

Considering the group of patients with chronic gastritis $(n=29)$, no correlation was found between degree of activity of gastritis and extent of DNA hypomethylation $(\mathrm{p}=0.39)$.

When searching for a correlation between DNA methylation level and degree of atrophy, we found that DNA from patients with moderate or severe atrophic gastritis $(n=8)$ incorporated more $\left({ }^{3} \mathrm{H}\right)$ methyl groups than DNA from patients with mild atrophy $(n=7)$ (440784 (37 657) v 305573 (38 584) dpm/ $\mu \mathrm{g} / \mathrm{DNA} ; \mathrm{p}=0 \cdot 01)$. Also, there was a trend towards DNA from patients with type III intestinal metaplasia $(n=5)$ to be more hypomethylated than DNA from patients with type I or II intestinal metaplasia $(n=10)$, although it did not reach statistical significance (438 796 (65 650) v 374159 (21 607) dpm/ $\mathrm{g} / \mathrm{DNA}$; $\mathrm{p}=0 \cdot 15) . H$ pylori infection did not seem to influence significantly the extent of DNA methylation in gastric mucosa as DNA from samples of infected patients was less hypomethylated than DNA from specimens of patients without histological evidence of $H$ pylori (323 674 (35 990) v 409079 (29 915) $\mathrm{dpm} / \mu \mathrm{g} / \mathrm{DNA} ; \mathrm{p}=0.09)$.

Considering cases with gastric carcinoma no correlation was found between DNA methylation status and stage or grade of differ- entiation. Hypomethylation of DNA tended to increase with aging $(r=0.25 ; \mathrm{p}=0.14)$ and DNA from samples of female patients was more hypomethylated but not significantly so $(p=0.07)$.

\section{Discussion}

Colorectal and gastric carcinogenesis are two distinct processes in the sense that in the first there is evidence that there is a field defect of the whole colonic mucosa that renders it more susceptible to neoplastic transformation. In the stomach only the mucosa undergoing atrophy and metaplastic changes is at increased risk. None the less, in both models of tumorigenesis, the mucosa undergoes a series of sequential changes before malignant transformation takes place. Thus, in this respect and similarly to what has been found in colorectal carcinogenesis, global DNA hypomethylation seems to occur early in the sequence of events that have been postulated to precede the development of intestinal type of gastric carcinoma. Our data show a graduated increase from normal mucosa, to superficial, and to atrophic gastritis, but there was no further increase in DNA hypomethylation in samples taken from patients with gastric carcinoma. In the colon, Feinberg $e t a l^{21}$ also showed a significant reduction in 5-methylcytosine content in colonic adenomas and adenocarcinomas compared with normal, paired matched mucosa, but no differences existed between benign and malignant neoplasms. By contrast, in cervical dysplasia and carcinoma, Kim and colleagues have shown that global DNA hypomethylation occurs only in the later stages of carcinogenesis (in high grade squamous intraepithelial lesions and invasive squamous cancer). ${ }^{24}$

Further supporting the hypothesis that DNA hypomethylation may be a significant event in gastric carcinogenesis, we found that the extent of DNA hypomethylation increased with degree of atrophy and, more importantly, DNA from biopsy specimens showing type III intestinal metaplasia was substantially more hypomethylated than DNA from biopsy specimens with type I/II intestinal metaplasia. Differences did not reach statistical significance probably due to few patients with type III intestinal metaplasia. Previous retrospective and prospective studies ${ }^{1-3}$ have shown that, compared with type I/II intestinal metaplasia, this type of intestinal metaplasia with incomplete cell differentiation and sulphomucin secretion, carries with it a significant risk of the intestinal type of gastric cancer. Retrospective studies found that type I and II intestinal metaplasia are common and prevalent in both benign and malignant conditions, ${ }^{40-42}$ whereas the incidence of type III intestinal metaplasia in gastric carcinoma is significantly higher than in chronic gastritis or gastric ulcer. In support of these data, Rokkas et al, ${ }^{1}$ in a prospective study, found that endoscopic surveillance of patients with type III intestinal metaplasia led to a significant increase in the rate of detection of early gastric cancer. For these reasons, certain authors think that the presence of these 
lesions should lead to prolonged endoscopic surveillance for early detection of gastric cancer.

Although global and gene specific DNA hypomethylation have been proposed as essential steps in the development of several human neoplasms, the exact part that hypomethylation plays in carcinogenesis remains unclear. ${ }^{16-18}$ One possible mechanism might be related to altered gene expression that accompanies changes in DNA methylation as loss of DNA methyl groups has been shown, in some instances, to increase transcription of certain proto-oncogenes, thereby increasing the risk of malignant transformation. ${ }^{29-33}$ Thus the global DNA hypomethylation in the early stages of gastric carcinogenesis found in this study could be associated with hypomethylation and increased transcription of certain oncogenes implicated in gastric cancer. Future studies examining the methylation status of these oncogenes are warranted.

Biopsy specimens from patients with chronic gastritis have a heavy inflammatory infiltrate and, therefore, we cannot exclude that the differences found between the several samples could be ascribed to different proportions of inflammatory cells present in the several specimens, especially in regard to the differences found between normal subjects and those with superficial gastritis. However, the fact that no correlation was found between degree of DNA methylation and activity of gastritis is strongly against this hypothesis. Also, there was a trend towards specimens with $H$ pylori, which are usually associated with a denser inflammatory infiltrate, to exhibit a lower degree of DNA hypomethylation. Therefore, it is highly unlikely that the increase in global DNA hypomethylation in specimens with chronic gastritis is largely attributed to different proportions in inflammatory cells. By contrast, DNA from precursor lesions, which have been strongly associated with an increased risk of malignant transformation, such as gastric atrophy and type III intestinal metaplasia, were more heavily hypomethylated. This suggests that the changes in DNA methylation pattern may be a significant epigenetic phenomenon in the chain of events that precede the development of gastric cancer.

DNA hypomethylation has been experimentally induced by severe folate deficiency. ${ }^{39}$ Folate, in the form of methyltetrahydrofolate, is involved in the synthesis of methionine, which is a precursor of S-adenosylmethionine, the methyl group donor for several biological transmethylation reactions, including that of DNA. ${ }^{42}{ }^{43}$ This is thought to be the mechanism by which folate deficiency would increase the risk of malignant transformation at several sites such as the colon, the cervix, and the bronchial epithelium. ${ }^{2045-47}$ With regard to gastric carcinoma, epidemiological and case-cohort studies have suggested that a low consumption of fresh vegetables is associated to an increased risk of developing gastric cancer. ${ }^{48-50}$ Although it is usually accepted that this protective effect is related to the high content of vegetables in ascorbic acid and carotenoids, it is possible that the high content in folate might also account for some of the protection found.

Although the incidence of gastric adenocarcinoma is declining worldwide, ${ }^{51}$ this tumour still remains a major health problem in most countries. Portugal is one of the European countries with the highest incidences. The poor prognosis of advanced gastric carcinoma has not changed substantially over the years ${ }^{52}$ but this dismal outcome is in sharp contrast with the excellent five year survival rate of surgically treated early gastric cancer. Screening of large numbers of asymptomatic patients to detect gastric carcinoma in its early stages is not considered feasible apart from Japan, where about $25 \%$ of all cases of gastric carcinoma are diagnosed in mass surveys. ${ }^{53}$ It is therefore necessary to identify subgroups of patients with an increased risk of developing gastric carcinoma such as those with chronic atrophic gastritis and type III intestinal metaplasia, in whom the development of surveillance programmes could be cost effective. Furthermore, in an attempt to reverse the process of malignant transformation, these patients could be included in chemoprevention trials designed to change the course of gastric carcinogenesis. Intermediate biomarkers such as global DNA methylation level could be useful in monitoring the response to these invervention studies.

1 Craanen ME, Blok P, Dekker W, Ferweda J, Tytgat GNJ Prevalence of subtypes of intestinal metaplasia in gastric antral mucosa. Dig Dis Sci 1991; 36: 1529-36.

2 Rokkas T, Filipe MI, Sladen GE. Detection of an increased incidence of early gastric cancer in patients with intestinal metaplasia type III who are closely followed up. Gut 1991; 32: 1110-3.

3 Sipponen P, Kekki M, Siurala M. Atrophic chronic gastritis and intestinal metaplasia in gastric carcinoma. Comparison with a representative population sample. Cancer 1983; 52: 1062-8.

4 Correa P. A model for gastric cancer epidemiology. Lancet 1975 ; i: $58-9$.

5 Correa P, Haenszel W, Cuello C, et al. Gastric precancerous process in a high risk population: cross sectional studies. Cancer Res 1990; 50: 4731-6.

6 Correa P, Haenszel W, Cuello C, et al. Gastric precancerous process in a high risk population: cohort follow-up. Cancer Res 1990; 50: 4737-40.

7 Correa P. Human gastric carcinogenesis: a multistep and multifactorial process-first American cancer society award lecture on cancer epidemiology and prevention. Cancer Res 1992; 52: 6735-40.

8 Sipponen P, Kekki M, Hapakoski J. Gastric cancer risk in chronic atrophic gastritis: statistical calculations of crosssectional data. Int $¥$ Cancer $1985 ; 35: 173-7$.

9 Sipponen P, Seppala K, Varis K, et al. Intestinal metaplasia with colonic-type sulphomucins in the gastric mucosa; its association with gastric carcinoma. Acta Pathol Microbiol Scand 1980; 88: 217-24.

10 Filipe MI, Jass JR. Intestinal metaplasia subtypes and cancer risk. In: Filipe MI, Jass JR, eds. Gastric carcinoma. Edinburgh: Churchill Livingstone, 1986: 87-115.

11 Correa P, Shiao Y. Phenotypic and genotypic events in gastric carcinogenesis. Cancer Res 1994; 54 (suppl): 1941-3.

12 Tahara E. Molecular mechanism of stomach carcinogenesis. f Cancer Res Clin Oncol 1993; 119: 265-72.

13 Rhyu MG, Park WS, Jung YJ, Choi SW, Meltzer SJ. Allelic deletions of MCC/APC and p53 are frequent late events deletions of MCC/APC and p53 are frequent late events
in human gastric carcinogenesis. Gastroenterology 1994; 106: 1584-8.

14 Oda $N$, Tsuino $T$, Tsuda $T$, Yoshida $K$, Nakayama $H$ Yasui W, Tahara E. DNA ploidy pattern and amplification of ERBB and ERBB2 genes in human gastric carcinomas. Virchows Arch B Cell Pathol 1990; 58: 273.

15 Hongyo T, Buzard GS, Palli D, Weghorst CM, Amorosi A Galli $M$, et al. Mutations of the K-ras and p53 Genes in gastric adenocarcinomas from a high-incidence region around Florence, Italy. Cancer Res 1994; 55: 2665-72.

16 Counts JL, Goodman JI. Alterations in DNA methylation may play a variety of roles in carcinogenesis. Cell 1995; 83: $13-5$. 
17 Laird PW, Jackson-Grusby L, Fazelli A, Dickinson SL, Jung WE, Li E, et al. Suppression of intestinal neoplasia by DNA hypomethylation. Cell 1995; 81: 197-205.

18 Fergusson AT, Lapidus RG, Baylin SB, Davidson NE. Cancer Res 1995; 55: 2279-83.

19 Gama-Sosa MA, Slagel VA, de Bustros A, Trewin RW, Oxenhandler R, Kuo, et al. The 5-methylcytosine content of DNA from human tumors. Nucleic Acid Res 1983; 11: of DNA

20 Cravo M, Fidalgo P, Pereira AD, Gouveia-Oliveira A, Chaves, et al. DNA methylation as an intermediate biomarker in colorectal cancer: modulation by folic acid. Eur f Cancer Prev 1994; 3: 473-9.

21 Feinberg AP, Gerrke CW, Kuo KC, Ehrlich M. Reduced genomic 5-methylcytosine content in human colonic neoplasia. Cancer Res 1988; 48: 1159-61.

22 Goelz SE, Vogelstein B. Hypomethylation of DNA from benign and malignant human colon neoplasms. Science 1985; 228: 187-90.

23 Feinberg AP, Vogelstein B. Hypomethylation of ras oncogenes in primary human cancers. Biochem Biophys oncogenes in primary human

$24 \mathrm{Kim}$ YI, Giuliano A, Hatch K, Schneider A, Nour MA, et al. Global DNA hypomethylation increases progressively in cervical dysplasia and carcinoma. Cancer progressively in cerv

25 Sharrard RM, Royds JA, Rogers S, Shorthouse AJ. Patterns of methylation of the c-myc gene in human colorectal cancer progression. $B r \mathcal{F}$ Cancer 1992; 65: 667-72.

26 Silverman AL, Park J-G, Hamilton SR, Gazdar AF, Luk GD, Baylin SB. Abnormal methylation of the carcitonin gene in human colonic neoplasms. Cancer Res 1989; 49: 3468-73.

27 de Bustros A, Nelkin BD, Silverman A, Ehrlich G, Poiesz B, Baylin SB. The short arm of chromosome 11 is a "hotspot" for hypermethylation in human neoplasia. Proc Natl spot" for hypermethylation in hum

28 Baylin SB, Makos M, Wu J, Yen R-CW, de Bustros A Vertino $\mathrm{P}$, et al. Abnormal patterns of DNA methylation in human neoplasia: potential consequences for tumor in human neoplasia: potential consequence

29 Doerfler W, Toth M, Kochanek S, Achten S, Freisem-Rabien U, Behn-Krappa A, et al. Eukaryotic DNA methylation: facts and problems. FEBS Lett 1990; 268: 329-33.

30 Razin A, Cedar H. DNA methylation and gene expression. Microbiol Rev 1991; 55: 451-8.

31 Bird A. The essentials of DNA methylation. Cell 1992; 70: 5-8.

32 Cedar H. DNA methylation and gene activity. Cell 1988; 53: 3-4.

33 Razin A, Szyf M. DNA methylation patterns. Formation and function. Biochem Biophys Acta 1984; 782: 331-42.

34 Correa P. The epidemiology and pathogenesis of chronic gastritis. Three etiologic entities. Front Gastroenterol Res 1980; 6: 98-108.

35 Lauren $P$. The two histological main types of gastric carcinoma: diffuse and so-called intestinal-type carcinoma. Acta Pathol Microbiol Scand 1965; 64: 31-49.
36 Spiessl B, Beahrs OH, Hermanek P, Hutter RVP, Scheibe O, Sobin LH, et al. TNM atlas. UICC. 3rd ed. Berlin: Springer Verlag, 1992.

37 Filipe MI, Lake BD. Histochemistry in pathology. Edinburgh: Churchill Livingstone, 1983.

38 Johns MB, Paulus-Thomas JE. Purification of human genomic DNA from whole blood using sodium genomic DNA from whole blood using sodium
perchlorate in place of phenol. Anal Biochem 1989; 180: perchlo.

39 Balaghi $M$, Wagner C. DNA methylation in folate deficiency. Biochem Biophys Res Commun 1993; 193: $1184-90$.

40 Imai $\mathrm{T}$, Maryama $\mathrm{H}$. Time trend in the prevalence of intestinal metaplasia. Cancer 1983; 52: 173-7.

41 Stemmermann GN, Hayashi T. Intestinal metaplasia of the gastric mucosa: a gross and microscopic study of its distribution in various disease states. 7 Natl Cancer Inst 1968; 41: 627-34.

42 Meister $\mathrm{H}$, Holubarsch $\mathrm{CH}$, Haferkamp $\mathrm{O}$, Schlag $\mathrm{P}$. Gastritis, intestinal metaplasia and dysplasia versus benign ulcer in stomach and duodenum and gastric carcinoma: a histotopographic study. Pathol Res Pract carcinoma: a histo

43 Miller JW, Nadeau MR, Smith J, Smith D, Selhub J. Folate deficiency-induced homocysteinemia in rats: disruption deficiency-induced homocysteinemia in rats: disruption
of $\mathrm{S}$-adenosylmethionine's coordinate regulation of of S-adenosylmethionine's coordinate regulation of

44 Balaghi M, Horne DW, Wagner C. Hepatic one-carbon metabolism in early folate deficiency in rats. Biochem $\mathcal{F}$ 1993; 191: 145-9.

45 M Cravo ML, Mason JB, Dayal Y, Hutchinson M, Smith D, Selhub J, Rosenberg IH. Folate deficiency enhances the development of colonic neoplasia in dimethylhydrazine-treated rats. Cancer Res 1992; 52: 5002-6.

46 Butterworth CE, Hatch $\mathrm{KD}$, Macaluso $M$, Cole $P$, Sauerlich HE, Soog SJ, et al. Folate deficiency and cervical dysplasia. $¥ A M A$ 1992; 267: 528-33.

47 Heimburger DC Alexander CB, Birch R, Butterworth CE $\mathrm{Jr}$, Bailey WC, Krumdieck CL. Improvement in bronchial $\mathrm{Jr}$, Bailey WC, Krumdieck CL. Improvement in bronchial squamous metaplasia in smokers treated
vitamin $\mathrm{B} 12 . \mathfrak{F} A M A$ 1988; 259: $1525-30$.

48 Demirer T, Icli F, Uzunalimoglu, Kucuk O. Diet and stomach cancer incidence. Cancer 1990; 65: 2344-8.

49 Ramon JM, Serra L, Cerdo C, Oromi J. Dietary factors and gastric cancer risk. Cancer 1993; 71: 1731-5.

50 Chyou PH, Nomura AMY, Hankin JH, Stemmermann. A case-cohort study of diet and stomach cancer. Cancer Res 1990; 50: 7501-4.

51 National Cancer Institute. Annual cancer statistics review: 1973-1991. Bethesda, MD: Department of Health and Human Services, 1994. (DHHS publ No $27 \mathrm{NIH}$ 94-2789).

52 Fuchs CS, Mayer RJ. Gastric carcinoma. N Engl f Med 1995; 333: 32-41.

53 Kaibara N, Kawagushi H, Nishidoi H, Kimura O, Okamoto T, Koga S, Fukumoto S. Significance of mass survey for gastric cancer from the standpoint of surgery. Am $\mathcal{F}$ Surg 1981; 142: 543-5. 